\title{
Usefulness of porphyry and amphibolites as a component of concrete for airfield pavements
}

\author{
Matgorzata Linek ${ }^{1, *}$, Piotr $\mathrm{Nita}^{2}$, Pawet Wolka ${ }^{1}$, and Wojciech Żebrowski ${ }^{1}$ \\ ${ }^{1}$ Kielce University of Technology, Faculty of Civil Engineering and Architecture, Department of \\ Transportation Engineering, Tysiąclecia Państwa Polskiego Street 7,25-314 Kielce, Poland \\ ${ }^{2}$ Air Force Institute of Technology, Księcia Bolesława Street 6, 01-494 Warsaw, Poland
}

\begin{abstract}
Coarse aggregate used as part of cement concrete is of primary significance for the obtained parameters of hardened concrete. In case of concretes intended for airfield pavements, the application of granite grit is recommended. Alternative to this type of aggregate in the form of porphyry and amphibolites aggregate was suggested. In order to assess the suitability of different aggregate types for concrete mixes, their bulk density, absorbability, polishing resistance, abrasion and crushing resistance were determined. Also, the internal structure of the suggested aggregates and its influence on changes of hardened concrete composite structure were subject to the assessment. The influence of aggregate type on the structure of cement matrix and contact areas between the matrix and aggregate grains were specified. The observed changes, in case of the internal structure of concretes based on porphyry and amphibolites aggregates, with reference to granite aggregate, resulted in changes of mechanical and physical parameters. Analyses included the determination of bulk density, absorbability, compression, bending and splitting resistance. According to the obtained laboratory test results, the significant influence of the aggregate type applied to the mix on parameters of hardened concrete, with regard to the application thereof to the airfield pavements was proved.
\end{abstract}

\section{Introduction}

The article is aimed at the assessment of the suitability of the suggested aggregates in the composition of cement concrete intended for airfield pavements. The basic properties of granite, porphyry and amphibolites aggregate were determined. It was assessed whether the applied aggregate influences the change of parameters of internal structure of hardened cement concrete, the change of physical and mechanical properties of concrete intended for air field pavements.

\footnotetext{
${ }^{*}$ Corresponding author: linekm@tu.kielce.pl
} 


\section{Materials}

Analyses focused on three series of various types of aggregate. Series labelled A was amphibolites aggregate fraction of $2 / 8 \mathrm{~mm}$ and $8 / 16 \mathrm{~mm}$, series $\mathrm{P}$ was porphyry aggregate of grain-size distribution of $2 / 8 \mathrm{~mm}$ and $8 / 16 \mathrm{~mm}$, while series $\mathrm{G}$ was the reference aggregate granite aggregate of grain-size distribution of $2 / 8 \mathrm{~mm}$ and $8 / 16 \mathrm{~mm}$. In case of the selected types of aggregate the following were determined: volume density $\left(\mathrm{Q}_{\mathrm{a}}\right)$ according to [1], absorbability (W) according to [2], abrasion resistance $\left(\mathrm{M}_{\mathrm{DE}}\right)$ according to [3] and crushing resistance (LA) according to [4].

The influence of the type of the applied aggregate on the change of concrete mix parameters was determined. The experiment assumed to perform three series of concrete mix. The first series was reference concrete mix (MG). Two consecutive series included concrete mix with granite aggregate substitute in the form of porphyry aggregate (series MP) and amphibious (series MA). The tests included: mix density using cylinder of $8 \mathrm{dm}^{3}$ capacity according to [5], consistency using concrete slump method according to [6], air contents using manometer method according to [7] The prepared concrete mix series MG,

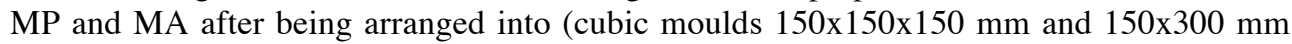
according to [8]) were subject to standard curing [9] for the assumed research periods ( 7 and 28 days).

The experiment assumed to perform three series of concrete. The first series was reference concrete (CG), in accordance with the requirements of [10]. Two consecutive series included concrete with aggregate substitute in the form of porphyry aggregate (series $\mathrm{CP}$ ) and amphibious aggregate (series CA). Concretes for airport pavements were analyzed. The determined concrete parameters included the following: volume density $\left(\varrho_{o}\right)$ according to [11], absorbability $(\mathrm{N})$ according to [10], compressive strength $\left(\mathrm{f}_{\mathrm{cm}}\right)$ according to [12], splitting tensile strength $\left(\mathrm{f}_{\mathrm{ct}}\right)$ according to [13] and concrete bending strength $\left(\mathrm{f}_{\mathrm{cf}}\right)$ after diversified curing periods.

Selected samples of $\mathrm{Cg}, \mathrm{CP}$ and $\mathrm{CA}$ concrete were observed in scanning electron microscope. Preparation surface subject to observations by means of scanning electron microscope was not less than $1.0 \mathrm{~cm}^{2}$, and the scope of magnifying power was assumed between 200x to 100000x. [14]

\section{Characteristics of aggregates}

The fraction is distinguished by irregular, angular and sharp shape. It was concluded that fractions of porphyry grit do not contain quartz crystals - fig. 2a. Based on the chemical microanalysis of the analysed porphyry grit, the occurrence of the following elements, i.e. oxygen, sulfur, aluminum, potassium, carbon, sodium, calcium, magnesium was proved (figure 2).
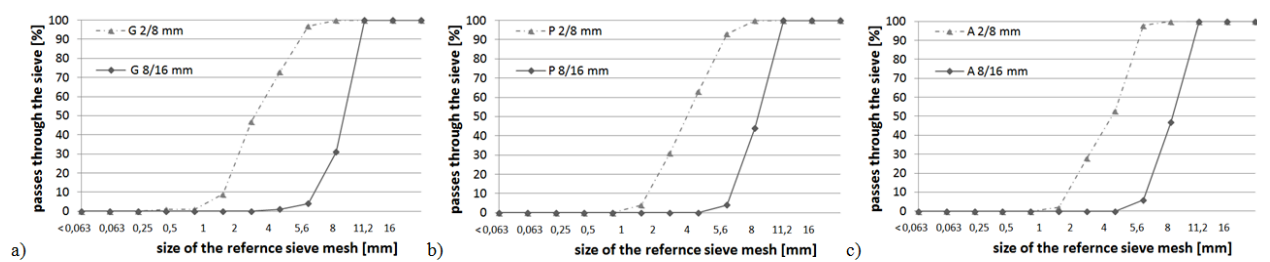

Fig. 1. Designed aggregate mixture curve, together with limit curves (lower and upper) - a) MG, b) MP, c) MA. 
a) SEM image

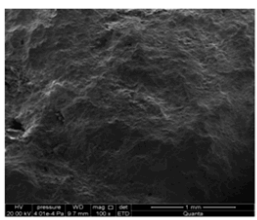

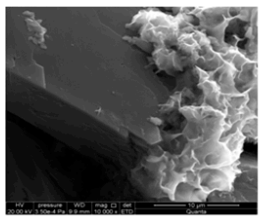

b) chemical microanalysis
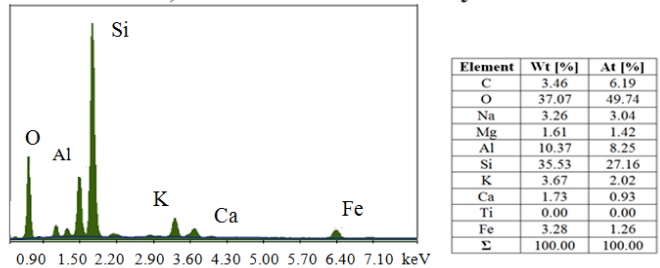

Fig. 2. Structure of the examined porphyry aggregate: a) SEM image of cement grain from SEM and b) image of chemical microanalysis.

According to SEM observations it was proved that grit fraction is distinguished by angular shape and medium-blastic structure - fig. 3a. Based on the chemical microanalysis of the analysed amphibolite grit, the occurrence of the following elements, i.e. oxygen, silicon, iron, aluminum, calcium, titanium, carbon, magnesium and sodium was proved (figure $3 b$ ).

a) SEM image

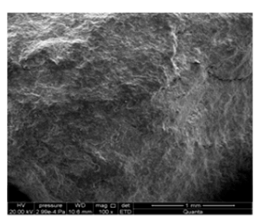

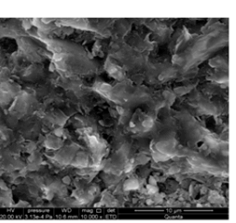

b) chemical microanalysis

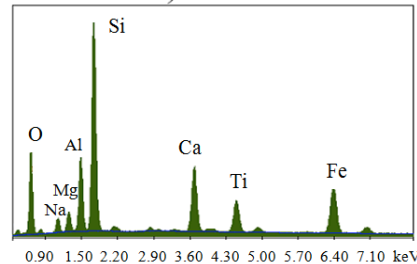

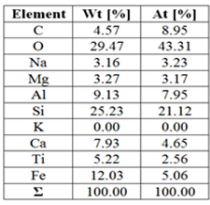

Fig. 3. Structure of the examined amphibolite aggregate: a) SEM image of cement grain from SEM and b) image of chemical microanalysis.

\section{Methodology and test results}

Composition of concretes included: cement CEM I 42.5 MSR/NA (fig. 4), sand, water according to [15], air entraining agent and plasticizing admixture. Aggregate grading composition of mix series MG, MP and MA was selected according to the guidelines of [10] taking into consideration limit curves of good grain size distribution (Figure 5).

a) SEM image


Fig. 4. Structure of the examined cement: a) SEM image of cement grain from SEM and b) image of chemical microanalysis. b) chemical microanalysis

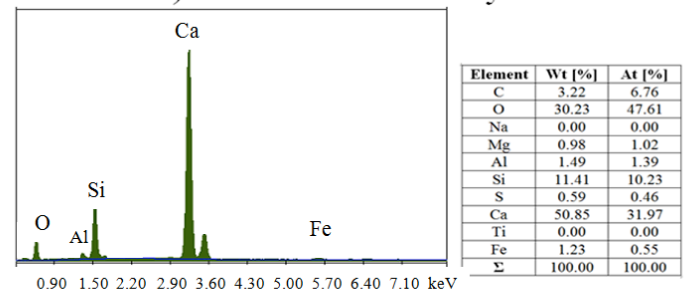



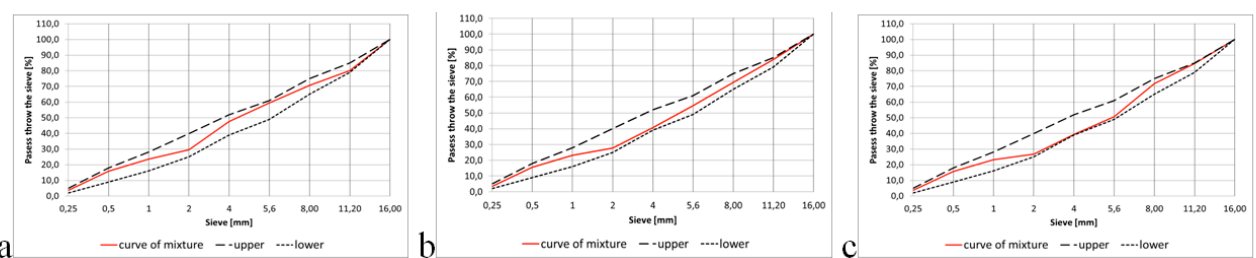

Fig. 5. Designed aggregate mixture curve, together with limit curves (lower and upper): a) MG, b) $\mathrm{MP}, \mathrm{c}) \mathrm{MA}$.

Quantity selection of the remaining components (table 1) was based on experimental methods maintaining the consistency of reference mix at S1 level and taking into consideration the exposure class XF4, with the air amount between 4,5-5,5\%.

Table 1. Compositions of the designed mixes of the following series MG, MK and MS.

\begin{tabular}{|c|c|c|c|}
\hline \multirow{2}{*}{ Components } & MG & MP & MA \\
\cline { 2 - 4 } & {$\left[\mathrm{kg} / \mathrm{m}^{3}\right]$} & {$\left[\mathrm{kg} / \mathrm{m}^{3}\right]$} & {$\left[\mathrm{kg} / \mathrm{m}^{3}\right]$} \\
\hline Cement CEM I 42,5N MSR/NA & 375 & 375 & 375 \\
\hline Fine aggregate 0/2mm & 518 & 512 & 555 \\
\hline Granit 2/8mm & 845 & - & - \\
\hline Granit 8/16mm & 557 & - & - \\
\hline Porphyry & - & 834 & - \\
\hline porphyry & - & 550 & - \\
\hline amphibolite & - & - & 505 \\
\hline amphibolite & - & - & 150 \\
\hline Water & 150 & 150 & 1.69 \\
\hline plasticizer & 1.69 & 1.69 & 1.13 \\
\hline Aerating agent & 0.94 & 1.13 & \\
\hline
\end{tabular}

\subsection{Assessment of parameters of the analyzed aggregates}

According to the conducted tests (table 2) in case of the analyzed aggregate types it was proved that amphibolites aggregate is distinguished by the greatest volume density and porphyry aggregate by the lowest volume density. In case of absorbability, comparable parameters were obtained in case of granite and amphibolites aggregates, while in case of porphyry aggregate this value is higher and exceeds $2 \%$. 
Table 2. Parameters of aggregates.

\begin{tabular}{|c|c|c|c|c|c|c|c|}
\hline parameters & j.m. & \multicolumn{2}{|c|}{ G } & \multicolumn{2}{|c|}{ P } & \multicolumn{2}{|c|}{ A } \\
\hline $\mathrm{Q}_{\mathrm{a}}$ & $\mathrm{Mg} / \mathrm{m}^{3}$ & \multicolumn{2}{|c|}{2.65} & \multicolumn{2}{|c|}{2.60} & \multicolumn{2}{|c|}{2.95} \\
\hline $\mathrm{W}$ & $\%$ & \multicolumn{2}{|c|}{0.60} & \multicolumn{2}{|c|}{2.70} & \multicolumn{2}{|c|}{0.60} \\
\hline $\mathrm{M}_{\mathrm{DE}}$ & - & 8.46 & $\mathrm{M}_{\mathrm{D} 10}$ & 8.96 & $\mathrm{M}_{\mathrm{D} 10}$ & 5.16 & $\mathrm{M}_{\mathrm{D} 10}$ \\
\hline $\mathrm{LA}$ & - & 34.8 & $\mathrm{~L}_{\mathrm{A} 35}$ & 9.49 & $\mathrm{~L}_{\mathrm{A} 15}$ & 15.08 & $\mathrm{~L}_{\mathrm{A} 20}$ \\
\hline
\end{tabular}

According to the conducted tests (table 2) in case of the analyzed aggregate types it was proved that amphibolites aggregate is distinguished by the greatest volume density and porphyry aggregate by the lowest volume density. In case of absorbability, comparable parameters were obtained in case of granite and amphibolites aggregates, while in case of porphyry aggregate this value is higher and exceeds $2 \%$.

\subsection{Assessment of the influence of aggregate type on the properties of concrete mixes}

According to the obtained laboratory test results (table 3) it was proved that the air content in all mixes complies with standard requirements [10]. In case of MG mix, the air content was the lowest and it was $4.5 \%$. Significant diversification was proved in case of volume density. Mix of MA series was distinguished by the highest parameter, while the mix of MP series was distinguished by the lowest parameter. The difference was 7\%. Based on the obtained results, no significant influence of the aggregate type on the concrete mix consistency was proved. In case of all analyzed mixes, the consistency defined in experimental test corresponded to $\mathrm{S} 1$ class.

Table 3. Parameters of mixtures.

\begin{tabular}{|c|c|c|c|}
\hline mixture & Density $\left[\mathbf{k g} / \mathbf{m}^{3}\right]$ & Consistency $[\mathbf{m m}]$ & Air content $[\%]$ \\
\hline MG & 2392 & 11 & 4.5 \\
\hline MP & 2280 & 10 & 5.5 \\
\hline MA & 2460 & 10 & 5.5 \\
\hline
\end{tabular}

\subsection{Assessment of influence of the suggested aggregates on the selected physical and mechanical parameters of hardened concrete}

During scientific research, the amount of the required samples was determined using student's T-distribution assuming the significance level of 0.05 . The minimum essential number of samples ranged between 4 and 5, depending on the type of the conducted test. In case of such assumptions, 6 samples were selected, which, each time, were intended for the laboratory tests. According to the obtained experimental test results (table 4) it was proved that the type of coarse aggregate significantly influences volume density of hardened concrete. Concretes of CG series were distinguished by the highest volume density, while concretes of $\mathrm{CP}$ series of the lowest volume density. The examined feature is also strictly 
dependent on the length of curing period. The diversification of the examined feature in case of CG and CP concrete type was approx. $113 \mathrm{~kg} / \mathrm{m}^{3}$ and $130 \mathrm{~kg} / \mathrm{m}^{3}$ after 7 and 28 days accordingly. Type of aggregate also influences the amount of water absorbed by concrete. In case of the examined aggregate type, it was proved that concrete series CA and CP are distinguished by the lowest absorbability, the amount of which does not exceed $3.5 \%$. Concrete of CG series is distinguished by the absorbability of $4 \%$. It should be emphasised that all of the analyzed concrete types complied with the requirements of [10] standard with regard to absorbability.

Table 4. Average hardened concrete density and absorbability of series CG, CK and CS during diversified curing periods ( 7 and 28 days).

\begin{tabular}{|c|c|c|c|c|c|c|}
\hline \multirow{2}{*}{ concrete } & \multicolumn{4}{|c|}{ Density, [kg/m $\left.\mathbf{m}^{3}\right]$} & Absorbability, [\%] \\
\cline { 2 - 7 } & \multicolumn{2}{|c|}{7} & \multicolumn{2}{|c|}{28} & \multicolumn{2}{c|}{28} \\
\cline { 2 - 7 } & $\bar{X}$ & $\sigma$ & $\bar{X}$ & $\sigma$ & $\bar{X}$ & $\sigma$ \\
\hline CG & 2459 & 11.048 & 2460.38 & 9.033 & 4.0 & 0.090 \\
\hline CP & 2346 & 11.860 & 2330.12 & 11.214 & 3.4 & 0.168 \\
\hline CA & 2450 & 2.534 & 2446.93 & 3.572 & 3.2 & 0.096 \\
\hline
\end{tabular}

The type of the coarse aggregate applied to the mix significantly influences the obtained mechanical parameters of hardened concrete. The growth of resistance in case of concretes analyzed after 7 and 28 days independent of the aggregate type retained on the comparable level of $7 \mathrm{MPa}$. Concrete of $\mathrm{CP}$ series was distinguished by the highest compressive strength, while concrete of CA series the lowest one. In case of the analysed concrete type of CP and CA series the diversification was approx. $20 \mathrm{MPa}$, both after 7 and 28 days of curing. Comparable tendency retains in case of the analyzed concretes with regard to splitting tensile strength (table 5). Concrete of $\mathrm{CP}$ series was distinguished by the highest resistance, while concrete of CA series of the lowest resistance.

Table 5. Average hardened concrete tensile splitting strength and compressive strength of series CG,

CK and CS during diversified curing periods (7 and 28 days).

\begin{tabular}{|c|c|c|c|c|c|c|c|c|}
\hline \multirow{2}{*}{ concrete } & \multicolumn{3}{|c|}{ Compressive strength, [MPa] } & \multicolumn{4}{|c|}{$\begin{array}{c}\text { Tensile splitting strength, } \\
\text { [MPa] }\end{array}$} \\
\cline { 2 - 10 } & \multicolumn{2}{|c|}{7} & \multicolumn{2}{|c|}{28} & \multicolumn{2}{|c|}{7} & \multicolumn{2}{|c|}{28} \\
\cline { 2 - 10 } & $\bar{X}$ & $\sigma$ & $\bar{X}$ & $\sigma$ & $\bar{X}$ & $\sigma$ & $\bar{X}$ & $\sigma$ \\
\hline CG & 50.1 & 1.522 & 57.0 & 1.300 & 3.9 & 0.136 & 4.3 & 0.350 \\
\hline CP & 59.2 & 1.281 & 67.9 & 1.917 & 4.2 & 0.372 & 4.8 & 0.091 \\
\hline CA & 40.6 & 1.464 & 47.3 & 2.182 & 3.4 & 0.218 & 3.8 & 0.224 \\
\hline
\end{tabular}

According to the analysis of the obtained test results it was proved that concrete of $\mathrm{CP}$ series is distinguished by the most favourable parameters. Compared to the recommended concrete of CG series, according to [10] standard, concrete of CP series has higher 
resistance parameters and is distinguished by comparable absorbability. Therefore, it can be the alternative for granite aggregate. The results obtained after the frost resistance test (table) are also the confirmation thereof. In case of the applied amphibolites aggregate the parameters obtained by concrete are significantly lower. The intent of using this type of aggregate should be preceded by detailed tests.

\subsection{Assessment of influence of aggregate type on concrete microsructure}

According to the conducted SEM observations it was proved that the type of aggregate contributes to the change of internal structure of cement matrix (fig. 6-8). The internal structure of concrete of CA series is distinguished by non-continuous contact areas between aggregate grains and cement matrix (fig. 8a). Hydrated calcium silicates occurs in the finegrained form. Contact areas between aggregate grains and cement matrix undergo cracking of the width up to $8 \mu \mathrm{m}$. Cement matrix undergo cracking of the width up to 6-7 $\mu \mathrm{m}$ (fig. 8c). Internal walls of air voids undergo cracking of the width up to $2-3 \mu \mathrm{m}$ (fig. $8 \mathrm{~b}$ ). Cement matrix, in case of concrete of $\mathrm{CP}$ series, is consistent and crystallization of hydrated calcium silicate occurs in fine-grained form (fig. 7c). Crystallization of ettringite with the length of single crystals of which is up to $3 \mu \mathrm{m}$, occurs in cement matrix. Contact areas between aggregate grains and cement matrix undergo cracking of the width up to $3 \mu \mathrm{m}$ (fig. 7a). Crystallization of ettringite (length up to $1 \mu \mathrm{m}$ ) and cracked walls of air void interior were proved (fig. 7b). Crystallization of ettringite (length up to $10 \mu \mathrm{m}$ ) and cracked walls of air void interior were proved. Crystallization of ettringite (length up to $3 \mu \mathrm{m}$ ) and cracked walls of air void interior were proved (fig. 6b). Cement matrix, in case of concrete of CG series, is consistent and crystallization of hydrated calcium silicate occurs in finefibrous form (fig. 6c). Contact areas between aggregate grains and cement matrix undergo cracking of the width up to $3 \mu \mathrm{m}$ (fig. 6a).

a)
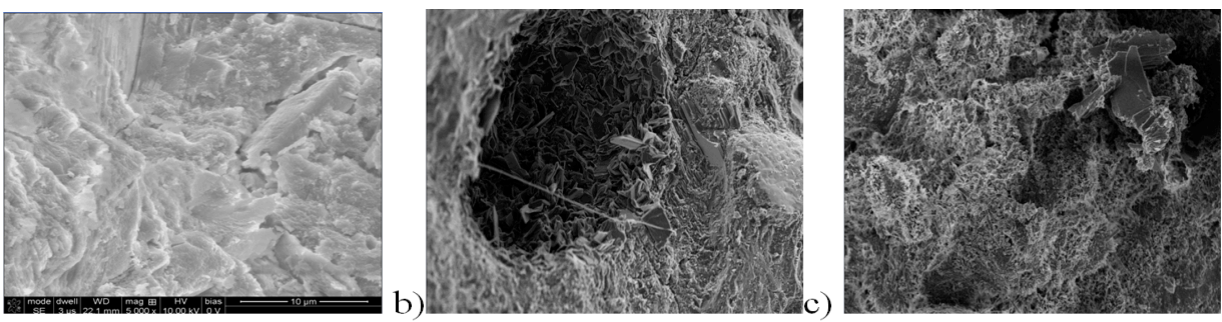

Fig. 6. Internal structure of cement concrete series CG: a) contact areas between cement matrix and aggregate grains, b) air pores, c) cement.

a)

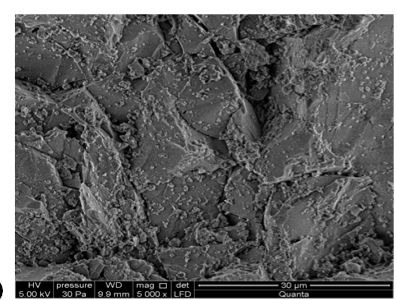

Fig. 7. Internal structure of cement concrete series CP: a) contact areas between cement matrix and aggregate grains, b) air pores, c) cement. 

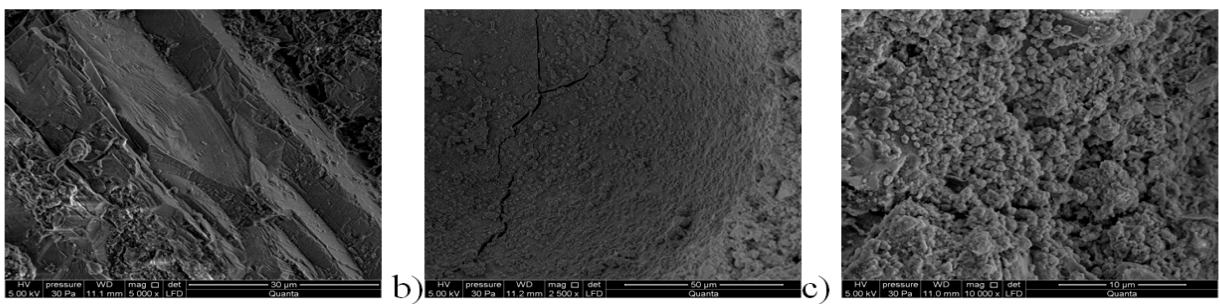

Fig. 8. Internal structure of cement concrete series CA: a) contact areas between cement matrix and aggregate grains, b) air pores, c) cement.

\section{Conclusions}

According to the conducted laboratory tests, the following conclusions have been reached: - porphyry aggregate composition contains oxygen, sulfur, aluminum, potassium, carbon, sodium, calcium, magnesium $\mathrm{O}, \mathrm{S}, \mathrm{Al}, \mathrm{K}, \mathrm{C}, \mathrm{Na}, \mathrm{Ca}, \mathrm{Mg}$ and amphibolite contains $\mathrm{O}, \mathrm{Fe}$, $\mathrm{Si}, \mathrm{Al}, \mathrm{Ca}, \mathrm{Ti}, \mathrm{C}, \mathrm{Mg}$ and $\mathrm{Na}$;

- applied aggregates favourably affect the changes of internal structure of concrete composite (contact areas between aggregate grains and cement matrix, crystallization of cement matrix, air void);

- significant influence of the used aggregates on the change of parameters of cement concrete intended for the airfield pavements was proved;

- aggregates porphyry used in concrete mix contribute to the increase of concrete ultimate compressive strength after standard curing period by $20 \%$, concrete tensile splitting strength after standard curing period by $9 \%$ and decrease of concrete absorbability by $0.6 \%$; - aggregates amphibolite used in concrete mix contribute to decrease of concrete ultimate compressive strength after standard curing period by $17 \%$, tensile splitting strength after standard curing period by $8 \%$ and decrease of concrete absorbability by $0.8 \%$.

\section{References}

1. PN-EN 1097-7 (2008)

2. PN-EN 1097-6 (2013-11)

3. PN-EN 197-1 (2012)

4. PN-EN 1097-2 (2010)

5. PN-EN 12350-6 (2011)

6. PN-EN 12350-2 (2011)

7. PN-EN 12350-7 (2011)

8. PN-EN 12390-1 (2013)

9. PN-EN 12390-2 (2011)

10. NO 17-A204 (2015)

11. PN-EN 12390-7 (2011)

12. PN-EN 12390-3 (2011)

13. PN-EN 12390-6 (2011)

14. M. Linek, IOP Conf. Series: Mat. Sc. Eng. 245, 032032 (2017)

15. PN-EN 1008 (2004) 